\title{
Correction to: Intrusion Detection System for MQTT Protocol Based on Intelligent One- Class Classifiers
}

\author{
Esteban Jove (D), Jose Aveleira-Mata (D), Héctor Alaiz-Moretón (D), \\ José-Luis Casteleiro-Roca (D), David Yeregui Marcos del Blanco (D), \\ Francisco Zayas-Gato (D), Héctor Quintián (D), \\ and José Luis Calvo-Rolle (1)
}

\section{Correction to: \\ Chapter "Intrusion Detection System for MQTT Protocol Based on Intelligent One-Class Classifiers" \\ in: J. M. Corchado and S. Trabelsi (Eds.): \\ Sustainable Smart Cities and Territories, LNNS 253, https://doi.org/10.1007/978-3-030-78901-5_22}

In the original version of the book, the following belated correction has been incorporated: The misspelled author name "Francico Zayas-Gato" has been corrected to "Francisco Zayas-Gato" in the Frontmatter, the Backmatter, and Chapter 22. 